\title{
A ampliação do conceito do político: para uma outra recepção da teoria crítica de Marx*
}

\author{
Rúrion Soares Melo \\ Doutor pelo Departamento de Filosofia da USP
}

Resumo: Procurando compreender a dinâmica dos conflitos contemporâneos presentes na sociedade civil e nos novos movimentos sociais, gostaríamos de apontar para uma outra recepção da teoria crítica marxista de acordo com uma reinterpretação do conceito do político em Marx, comparando sua formulação na Crítica da filosofia do direito de Hegel com os textos posteriores. Primeiramente, vamos lidar de forma breve com a questão da história dos efeitos na recepção da obra de Marx, chamando atenção para uma certa apropriação do jovem Marx no caso brasileiro. Em seguida, com base nas interpretações de Jean Cohen, pretendemos mostrar que, nos textos maduros, Marx delimitaria o próprio conceito do político em sua teoria da revolução a ponto de reduzi-lo a epifenômeno das relações econômicas. $\mathrm{O}$ problema principal consistiria em que, nessa delimitação, a ampliação do conceito do político para o campo da emancipação social permaneceria presa a um estreito conceito de práxis, pois o potencial emancipatório permaneceria subordinado às noções de "trabalho", de "desenvolvimento das forças produtivas" e, conseqüentemente, à teoria das classes.

Palavras-chave: Karl Marx, conceito do político, emancipação, teoria das classes, novos movimentos sociais
Abstract: In order to understand the dynamics of the contemporary conflicts around civil society and the new social movements, we would like to point to an other reception of marxian critical theory according to a reinterpretation of Marxs's concept of politics and compare his young formulation in Critic of Hegel's Philosophy of Right with the later texts. First, we take into account briefly the question of the history of effects in the reception of Marx's works. After that, based on the the interpretation of Jean Cohen, we intend to show that, in the mature texts, Marx restricts the concept of politics in his theory of revolution and reduces it to an "epiphenomenon" of the economic relations. In restricting it, the increase of the concept of politics to the social emancipation would remain attached to the notions of "labor", "development of productive forces" and, consequently, the theory of social class.

Keywords: Karl Marx, concept of politics, emancipation, class theory, new social movements

* Agradecemos a Ricardo Terra pelas críticas e sugestões feitas ao presente artigo. 
Não é novidade para estudiosos do marxismo que, ao tomar de empréstimo da economia política argumentos com os quais denunciam a ordem do direito burguês como expressão jurídica de relações injustas, Marx ampliou ao mesmo tempo o próprio conceito do que seja o político. ${ }^{1}$ Pois o conceito do político não estaria mais circunscrito pelas análises e fenômenos referentes à tradição jurídico-política burguesa, mas abrangeria fundamentalmente os processos sociais que residem na base econômica da sociedade: a emancipação humana não ocorreria no interior do campo tradicional da política, como uma emancipação política, mas sim aconteceria como emancipação social, como libertação das condições sociais desiguais e opressoras às quais estão submetidos os indivíduos. A intuição fundamental de Marx na sua crítica da sociedade civil consistiria em mostrar que o problema da democracia e da liberdade não poderia ser sanado sem que também fosse solucionada a "questão social". ${ }^{2}$ Pois a emancipação política (que resultou da Revolução Francesa) significava apenas a emancipação das restrições políticas impostas pelo feudalismo, de sorte que "o homem", diz Marx, "não se libertou da religião; ele obteve liberdade de religião. Ele não se libertou da propriedade; ele obteve liberdade de propriedade. Ele não se libertou do egoísmo do mercado; ele obteve liberdade de mercado". ${ }^{3}$ Seria necessário, portanto, dar um passo além e vincular tal emancipação política parcial a uma posterior revolução social: "apenas quando o indivíduo real (...) reconhecer e

1. As críticas feitas a Marx, principalmente a partir de 1989, insistem em descartar de uma vez por todas a possibilidade de uma alternativa política no interior do marxismo. De acordo com Helmut Dubiel - para ficarmos com apenas um exemplo - a "intelligentzia ocidental (...) tem de entender que o modelo liberal de democracia constitui a referência de todas as futuras estratégias políticas". Dubiel, H. Ungerwißheit und Politik. Frankfurt/M: Suhrkamp, 1994, p. 93.

2. "A noção central dizia respeito à 'questão social', diferentemente de uma mera preocupação com o liberalismo político, a liberdade, o radicalismo filosófico ou religioso, etc". Draper, H. Karl Marx's theory of revolution: The politics of social classes. New York: Monthly Review Press, 1978, p. 97.

3. Marx, K. Die Judenfrage. In: Engels, F.; Berlin: Dietz Verlag, 1961, p. 369. . Marx-Engels Werke. Band 1. 
organizar suas forces propres como poder social, e por sua vez o poder social não se dividir mais na forma do poder politico, apenas então a emancipação humana será consumada". ${ }^{4}$

Parecia claro que sua teoria da emancipação procurou ser compreendida como um importante esforço de vincular uma análise sistemática da reprodução e autovalorização do capital ao movimento proletário e a luta por uma democracia política efetiva. Mas, ainda que essa ampliação do conceito do político seja um dos passos mais importantes a serem mantidos por uma teoria com orientação emancipatória, não é tarefa simples entender atualmente sua abrangência nem interpretar sua configuração política no quadro dos conflitos contemporâneos: esse é o ônus da prova que recai sobre a atualidade da teoria crítica de Marx.

Podemos levar adiante uma reflexão sobre o conceito do político em Marx considerando dois pontos de partida interpretativos que, embora muitas vezes se encontrem vinculados, podem ser diferenciados. $\mathrm{Na}$ verdade, essa diferenciação e complementação de pontos de vista naturalmente não se restringem a uma abordagem metodológica específica às obras de Marx. O importante, neste caso, consiste no fato de ambos nos levarem a problemas semelhantes, mas que possuem graus de importância distintos para o exercício da reflexão filosófica. O primeiro ponto de partida, que chamaremos de marxologia por questão de convenção, privilegia uma interpretação estrutural de partes ou do desenvolvimento da totalidade da obra de Marx, obedecendo à autoridade e ao rigor conceitual dos textos de origem. Não podemos nos estender sobre essa questão no presente artigo. Todavia, exemplos paradigmáticos dessa abordagem podem ser encontrados em controvérsias metodológicas, como aquela levada a cabo por um

4. Idem, p. 370. A "questão social" como uma ampliação do conceito do político aparece formulada em $A$ questão judaica uma vez que aponta para um deslocamento da perspectiva estritamente política para a social. Ela se completa em toda obra de Marx, na verdade, como emancipação do proletariado, que ainda não tinha sido apresentado nesse texto. Porém, cabe notar que a retomada do jovem Marx sugerida adiante no presente artigo para uma reinterpretação contemporânea do conceito do político não está circunscrita ao quadro conceitual d'A questão judaica. 
dos mais reconhecidos comentadores de Marx, Hal Draper. A despeito da reconstrução monumental que Draper oferece em seus já seis volumes da Teoria da revolução de Karl Marx, o autor insistiu no prefácio do primeiro volume que não trataria em seu estudo do que Marx poderia ter dito (ou do que poderia ser deduzido de passagens recortadas de seus textos), mas que pretendia oferecer uma "interpretação completa e definitiva da teoria política de Marx" de uma interpretação conceitualmente rigorosa e, em grande medida, neutra no que concerne aos problemas e aos métodos aplicados. O curioso é que, na verdade, basta acompanhar os nomes mais importantes da história do marxismo para constatar que o esforço em empreender algo como uma marxologia pura pode se transformar em uma recepção determinada pelo contexto de surgimento e de aplicação da própria interpretação, com o que o observador fiel implodiria seu ponto de vista estruturalista em detrimento da perspectiva da história dos efeitos.

Entendemos que é justamente a partir da história dos efeitos que poderíamos aferir o ônus da prova da teoria da emancipação de Marx e sua ampliação do conceito do político. Parece não haver muita novidade nisso, uma vez que a própria história do marxismo se desenvolveu e sobreviveu em razão de seu potencial de atualização - o que significou passar por sucessivas modificações e metamorfoses. Alguns autores se recusaram a admitir esse ônus da pro$\mathrm{va}$, outros o enfrentaram apenas implicitamente, e tiveram aqueles que o entenderam como um desafio a ser explicitamente levado em consideração. Em todo caso, de um modo ou de outro, ele estava presente. Sabemos desde os trabalhos de Althusser que uma pretensa neutralidade epistemológica pode significar praticamente o seu contrário quando impulsionada pela disputa hermenêutica que visava, sub-repticiamente, à crítica da ideologia: a originalidade do filósofo francês consistiu no fato de sua interpretação orientar a

5. Draper, H. Karl Marx's theory of revolution I: The state and bureaucracy. New York: Monthly Review Press, 1977, p. 11. Draper retoma essa discussão em torno de uma possível "interpretação última" de Marx no prefácio do segundo volume. Cf. Draper, H. Karl Marx's theory of revolution II: The politics of social classes. New York: Monthly Review Press, 1978, p. 1-13. 
recepção dos textos de Marx num dado momento histórico na direção oposta à evolução política do Partido Comunista Francês, confrontando assim a "ortodoxia" partidária rigorosa contra certas inclinações "liberais" de uma teoria que reivindicava rigor apenas conceitual. ${ }^{6}$ Do mesmo modo, a "interpretação última" de Draper consistia numa reação ao novo reformismo social-democrata que orientava interpretações marxistas para legitimar o programa de bem-estar social. ${ }^{7}$ Os exemplos podem ser aludidos à exaustão de autor para autor, de época para época, e tratá-los em cada caso apenas deslocaria nossa atenção para aspectos menos essenciais da presente exposição.

Ora, a própria interpretação das obras de Marx é marcada pela história dos efeitos que é capaz de proporcionar, de modo que nunca o autor está plenamente transparente de uma vez por todas, mas se encontra em disputa em cada recepção - disputa que, na verdade, não se limita à sua interpretação interna, mas precisa, sobretudo, fornecer a mais adequada formulação do diagnóstico do tempo. Nesse sentido, a força da crítica de Marx não dependeria apenas da capacidade de apontar para práticas de transformação das relações sociais vigentes, mas também em produzir determinados diagnósticos do tempo. ${ }^{8}$ Essa articulação bem sucedida entre teoria e prática implode os limites de uma teoria única e pretensamente completa e nos força a um trabalho em que o culto a autores e temas é colocado em xeque por causa da complexidade da realidade social e da abrangência teórica capaz de trazer tal realidade ao conceito. Indo diretamente ao nosso ponto: o ônus da prova atualmente para o conceito do político de Marx reside, por um lado, na não confirmação de uma teoria do colapso capitalista, na crise da sociedade do trabalho e na recomposição orgânica da classe trabalhadora; e, por outro lado, na experiência do capitalismo tardio, na emergência de novos

6. Sobre a relação de Alhtusser com o PCF, cf. Anderson, P. Considerações sobre o marxismo ocidental. São Paulo: Boitempo, 2004, p. 59 e ss.

7. Cf. Draper, H. "New social-democrat reformism". In: New Politics, v2, n. 2.New York: 1963, p. 35-48.

8. Cf. Nobre, M. A teoria crítica. Rio de Janeiro: Jorge Zahar, 2004, p. 11. 
movimentos sociais, processos de democratização e dos desafios impostos pelo multiculturalismo, os quais também ampliariam o conceito do político da questão social para as lutas emancipatórias ligadas à questão cultural.

II

Existem muitas possíveis interpretações sobre o desenvolvimento da teoria de Marx e o que poderia significar essa ampliação do conceito do político. Interessa-nos, principalmente no caso uspiano, uma retomada da concepção do político a partir da interpretação do jovem Marx que uniu gerações tão distantes que levavam de Ruy Fausto a Marcos Nobre. ${ }^{9}$ Mesmo que tal abordagem permitisse à recepção marxista "de ultramar" romper o quadro epistemológico estabelecido por Althusser ${ }^{10}$, outros caminhos levavam à semelhante superação. Essa empreitada "contra Althusser"11 (fruto de problemas filosóficos genuinos, e não meramente reação ao autor francês) permitiu colocar em questão a divisão althusseriana a partir de seu proposto "corte epistemológico", em que se separaria os textos "ideológicos" do jovem Marx dos outros textos científicos da maturidade. A primeira ida ao jovem Marx foi a de Giannotti, o qual, ainda que estivesse interessado no Capital, dedicou todo um livro à análise, sobretudo, dos Manuscritos econômico-filosóficos. ${ }^{12}$ Embora também Giannotti fosse aos Manuscritos de 1844 antes de fazer do trabalho o modelo de todas as relações sociais ${ }^{13}$, seu percurso anti-althusseriano de uma ontologia unificada de matriz lógico-materialista nos importa menos agora do que um outro problema entrevisto inicial-

9. Cf. Arantes, P. Um departamento francês de ultramar. São Paulo: Paz e Terra, 1994, p. 314; Fausto, R. Marx - Lógica e politica. Tomo I. São Paulo: Brasiliense, 1987; e Nobre, M. Lukács e os limites da reificação. São Paulo: Ed. 34, 2001.

10. Cf. Althusser, L. Pour Marx. Paris: Librairie François Maspero, 1966.

11. Fazendo alusão a Giannotti, J. A. "Contra Althusser”. In: Giannotti, J. A. Exercícios de filosofia. Petrópolis/São Paulo: Vozes/CEBRAP, 1975.

12. Cf. Giannotti, J. A. Origens da dialética do trabalho. São Paulo: Difusão Européia do Livro, 1966.

13. Cf. Giannotti, J. A. Trabalho e reflexão. São Paulo: Brasiliense, 1984.

64 
mente por Ruy Fausto "ainda sob o efeito Althusser". Estratégia que também teria sido seguida por Michael Löwy ao pretender recuperar o conceito do político na obra do jovem Marx a partir de uma teoria da "autoemancipação do proletariado", adotando um caminho bem particular. ${ }^{14}$ Esse problema nos remente a uma questão fundamental para a teoria da emancipação de Marx e, por conseguinte, nos vincula novamente à interpretação de seu conceito do político.

Retomando. Ruy Fausto teria notado que a obra de juventude de Marx seria uma saída original para que pudéssemos fazer uma crítica do capitalismo contemporâneo. Mas não apenas isso. Ela poderia também contrabalançar a apresentação economicista do Capital que, partindo da análise do "fetichismo da mercadoria", conduziria a uma concepção de práxis política completamente reificada, pois aniquilaria a subjetividade humana já completamente mercantilizada. Esse problema era bem antigo na tradição marxista. Lembremos que, a partir da Segunda Internacional, a chamada tradição do marxismo ortodoxo defendeu a interpretação da teoria de Marx com base no Capital de acordo com a qual o processo revolucionário seria resultado natural da dinâmica capitalista. Ao passo que a Revolução Russa de 1917, por sua vez, mobilizou críticas da orientação revolucionária aos pressupostos mecanicistas do marxismo ortodoxo, abrindo um campo rico de interpretações nos textos do jovem Marx. ${ }^{15}$ Essa mistura entre subjetividade e capitalismo avançado, que tinha levado Marcuse en passant aos Manuscritos de 1844 (ou seja, ao Marx de juventude), levou também Ruy Fausto (não por acaso, em 1968) a pensar a articulação entre lógica e política com um instrumental conceitual diferente daquele do Capital. E quem insistiu nesse problema foi Marcos Nobre, ao mostrar que Lukács se voltaria às obras do jovem Marx

14. Cf. Löwy, M. A teoria da revolução no jovem Marx. Trad. de Anderson Gonçalves. Petrópolis: Vozes, 2002. E o que estava em jogo nessa outra via seguida por Löwy era, certamente, o movimento socialista europeu.

15. Cf. Reisberg, A. Von der I. zur II. Internationale. Die Durchsetzung des Marxismus um die Wiederherstelung der Arbeiterinternationale. Dietz, 1980; Vranicki, P. Geschichte des Marxismus. 2 Bände. Frankfurt/M: Suhrkamp, 1997. 
(referindo-se, nesse caso, à Miséria da Filosofia) justamente para poder apresentar a "determinação do sujeito revolucionário". ${ }^{16}$ Segundo Lukács, a superação em direção ao socialismo não poderia contar apenas com um determinismo estrutural do próprio capitalismo e prescindir da autodeterminação da práxis revolucionária da luta proletária. ${ }^{17}$

Temos aqui duas possíveis concepções concorrentes presentes na teoria da emancipação de Marx: a emancipação pensada como autoemancipação do proletariado, no qual este assume um papel ativo e constitutivo no processo revolucionário; e a emancipação formulada a partir da determinação econômica presente na dinâmica do capitalismo, a qual geraria as pré-condições técnicas, sociais e também organizacionais para a emancipação proletária. Muitos pensaram também aqui no Brasil, portanto, que essa colisão entre autodeterminação política e determinismo econômico seria resolvida caso voltássemos ao jovem Marx e recuperássemos lastros de subjetividade para o processo revolucionário, ou seja, o sujeito da revolução. ${ }^{18}$

Contudo, uma outra recepção da teoria crítica de Marx tornou essa ambivalência entre autoemancipação e as teses ortodoxas do determinismo estrutural mais explícita, e encontrou um modo de questionar o conceito do político vinculado à luta de classes segundo uma nova gramática da luta social. E aqui chegamos finalmente ao centro de nossas considerações. Partindo do que entendemos como formulações de uma teoria crítica renovada, gostaríamos de investigar, ainda que de sobrevôo, se a tendên-

16. Cf. Nobre, M. Lukács e os limites da reificação, pp. 73 e ss.

17. Cf. Lukács, G. História e consciência de classe. Trad. de Rodnei Nascimento. São Paulo: Martins Fontes, 2003, p. 63-104.

18. Note-se que as referências ao jovem Marx apontam sempre para interpretações e textos bem diversos. Para Giannotti e Ruy Fausto os Manuscritos de 1844 são particularmente importantes; Michel Löwy se volta à gênese da teoria da revolução que culmina nos textos de 1848, ou seja, antes da formulação do Marx maduro consolidada no Capital; Marcos Nobre chama atenção, valendo-se de Lukács, para o jovem Marx de $A$ miséria da filosofia. A seguir, veremos que a interpretação do jovem Marx estará ligada à Crítica da filosofia do direito de Hegel. 
cia de Marx a reduzir a interação política à instrumentalidade das relações de classe não o levaria a dissolver também o conceito ampliado do político nas determinações econômicas constitutivas da "questão social". É importante ressaltar, contudo, que essa crítica elaborada a partir da história dos efeitos implica que nos voltemos às obras de Marx necessariamente por uma via pouco ortodoxa, ou seja, com o olhar contemporâneo daqueles que recepcionam a teoria crítica marxista fundamentalmente com base na sua história dos efeitos. $\mathrm{Na}$ verdade, seguimos aqui outro rico campo de discussão - ainda pouco explorado no Brasil no que diz respeito à interpretação de Marx - que se desdobrou na França ${ }^{19}$, nos Estados Unidos ${ }^{20}$ e também fortemente na Alemanha ${ }^{21}$, para ficar com os exemplos mais significativos. ${ }^{22}$ Tal campo nos permitiria interpretar o conceito do político de Marx sem que a recuperação de suas obras de juventude ainda permanecesse presa à teoria das classes, e isso por duas razões: primeiramente, porque a teoria das classes seria determinada pelo próprio quadro economicista que muitos procuraram evitar ao se debruçarem nos textos de juventude; em segundo lugar, porque os conflitos políticos contemporâneos ampliariam o conceito do político para além do núcleo das relações entre capital e trabalho - núcleo que permaneceu quase

19. Cf. Baudrillard, J. Le miroir de la production. Ou, l'illusion critique du matérialisme historique. Paris: 1985; Castoriadis, C. L'Institution imaginaire de la Societé. Paris: Editions du Seuil, 1975.

20. Cf. Cohen, J. Class and civil society: The limits of marxian critical theory. Amherst: University of Massachussets Press, 1982; Benhabib, S. Critique, norm and utopia. New York: Columbia University Press, 1986; Rundell, J. Origins of modernity: The origins of modern social theory from Kant to Hegel to Marx. Cambridge, 1987.

21. Cf. Habermas, J. Erkenntnis und Interesse. Frankfurt/M: Suhrkamp, 1968; Meyer, T. Der Zwiespalt in der Marx'schen Emanzipationstheorie: Studie zur Rolle des proletarischen Subjekts. Kronberg: 1973; Honneth, A./Jaeggi, U. (org.). Theorien des Historischen Materialismus. Frankfurt/M: Suhrkamp, 1977; Lohmann, G. Indiferenz und Gesellschaft. Frankfurt/M: Suhrkamp, 1991.

22. Procuramos reconstruir esse debate de forma mais ampla e aprofundada em Melo, R. S. Sentidos da emancipação: Para além da antinomia revolução versus reforma. São Paulo. Tese (doutorado). FFLCH-USP, 2009. 
que integralmente intocado na história dos efeitos da teoria marxista sob tradição uspiana aludida rapidamente acima. ${ }^{23}$

Para os fins de um artigo esquemático como este, a interpretação de Jean Cohen nos parece particularmente representativa dos problemas a serem enfrentados por essa reatualização crítica da teoria marxista. A autora está reavaliando a concepção de emancipação em Marx com os olhos voltados à sua contemporaneidade, pretendendo assim contribuir para o desenvolvimento de uma nova teoria crítica da sociedade. Pois o que seria necessário à teoria crítica contemporânea diria respeito a uma nova reflexão teórica e uma nova interpretação da contestação social e da práxis política presentes na dinâmica política da sociedade civil. O conceito marxista de classe (bem como de sistema, totalidade e história) não possibilitaria mais um ponto de partida que permitisse "unificar, teórica e praticamente, a pluralidade de lutas e movimentos sociais na sociedade contemporânea". ${ }^{24}$ Não se trata de uma abordagem meramente externa aos textos, pois a autora trata os diferentes momentos e formulações da teoria de Marx apontando nuances e contradições inerentes ao desenvolvimento teórico e às suas conseqüências práticas. A tese da autora consiste em mostrar que temos de partir de Marx sem, contudo, permanecermos preso a ele, pois a ampliação do conceito do político desenvolvido na teoria das classes significaria paradoxalmente um estreitamento da política quando aplicada a contextos de conflito diferenciados. Os processos políticos e a dinâmica da luta entre as classes seriam tratados como meros epifenômenos das relações econômicas. É nessa tese mais geral de uma crítica feita ao paradigma produtivista de emancipação que vamos nos concentrar mais detidamente.

\section{III}

Cohen classifica os textos de Marx nos seguintes períodos: a crítica da sociedade civil anterior a 1844; a primeira crítica da

23. Atualmente, tais problemas são centrais na pauta de uma teoria crítica renovada e seus diferentes modelos. Para uma visão de conjunto, cf. Nobre, M. (org.) Curso livre de teoria critica. Campinas: Papirus, 2008.

24. Cohen, J. Class and civil society: The limits of marxian critical theory, p. xii. 
economia política em 1844; a teoria do materialismo histórico; e a teoria sistêmica do desenvolvimento capitalista nos Grundrisse e em O Capital, de 1857-1883. ${ }^{25}$ A autora mostra como cada um destes períodos pode ser interpretado como uma tentativa de Marx em desenvolver soluções ou alternativas a problemas surgidos, sobretudo, já em sua Critica da fllosofia do direito de Hegel. Em outras palavras, a teoria das classes responderia a problemas surgidos em formulações prévias de sua crítica da sociedade civil. O resultado desse desenvolvimento, que culmina na elaboração de O Capital, implicaria uma dissolução sociológica dos princípios normativos que regulavam a democracia, bem como uma compreensão funcionalista do Estado democrático de direito. Marx assumiria a existência de um sistema único - o modo capitalista de produção - cuja lógica penetraria e estruturaria todas as esferas da vida. $\mathrm{O}$ livro de Cohen permite traçar esse percurso nas obras de Marx por meio do qual este, privilegiando a economia política como objeto da crítica, não apenas teria compreendido a sociedade civil e o Estado como instituições meramente burguesas subordinadas aos imperativos de auto-valorização do capital, como identificaria também as relações de classe à lógica de reprodução capitalista. Da crítica da sociedade civil anterior a 1844 até seus textos tardios aconteceria assim uma gradativa redução da dinâmica própria da práxis política. Poderíamos notar uma provável "redução" e modificação do conceito de práxis nos diferentes períodos abordados ao entender como Marx o concebeu em seus primeiros textos, segundo a autora, como uma rica "interação política". Em 1844 tal conceito passa a significar principalmente "objetivação", e nos textos tardios varia, por fim, ainda entre "objetivação" e "luta de classes".

Para uma rápida compreensão do desenvolvimento político do jovem Marx, parece-nos fundamental partir da distinção hegeliana entre sociedade civil e Estado. Em sua Crítica da filosofia do direito de Hegel, Marx incorpora a formulação de Hegel da sociedade civil, entendendo-a como um sistema de necessidades organizado pela economia de mercado, por um sistema jurídico

25. Idem, p. 24. 
que assegurava liberdades civis, e associações e corporações da administração pública. ${ }^{26}$ Contudo, ele rejeita as versões liberais e hegeliana da liberdade política por restringirem a formação política da vontade ao âmbito das instituições do Estado, resultando assim em "alienação política". Isso porque Hegel procurou superar a fragmentação e desintegração resultante do princípio de autodeterminação individual, abstrata e egoísta que regia a sociedade civil, ao sublinhar a vinculação dos indivíduos a âmbitos do Estado em que se privilegiariam os interesses gerais sobre os particulares, gerando formas fundamentais de solidariedade social, tais como as corporações, a administração racional da justiça e a polícia. ${ }^{27}$ Não estava em questão na solução hegeliana a participação política ativa, pois a função das corporações consistia em garantir a integração social, mediando o Estado com os indivíduos essencialmente privatizados da sociedade civil.

Segundo a visão de Marx, o problema do sistema hegeliano das corporações e do Estado consistia no fato de que não davam conta dos princípios imanentes à sociedade civil explicitados pelo próprio Hegel: "A estabilidade alcançada por meio da institucionalização das associações voluntárias como corporações e que requeriam o reconhecimento do Estado (...) fatalmente solapa a independência da sociedade civil, cujos princípios são a individualidade, livre associação e auto-organização". ${ }^{28}$ Tratar-se-ia de uma "crítica imanente" das pretensões normativas articuladas por Hegel entre sociedade civil e Estado, embora com a recusa de sua separação. Em outras palavras, não se tratava de afirmar o elemento de atomização dos indivíduos na sociedade civil contra o Estado, mas sim denunciar este Estado como um falso universal, isto é, falsa solução para a fragmentação da sociedade civil. A tarefa de sua crítica consistiria em extrair as normas das instituições políticas

26. Cf. Hegel, G. W. F. Grundlinien der Philosophie des Rechts. Frankfurt/M: Suhrkamp, 1986, §§182-256. Cf. a interpretação fornecida em Honneth, A. Sofrimento de indeterminação: Uma reatualização da filosofia do direito de Hegel. Trad. de Rúrion Soares Melo. São Paulo: Esfera Pública, 2007, principalmente a parte III.

27. Cf. Hegel, G. W. F. Grundlinien der Philosophie des Rechts, §§ 230-256.

28. Cohen, J. Class and civil society: The limits of marxian critical theory, p. 28. 
modernas e contrastá-las com a forma institucional particular do Estado burguês que as realizariam apenas em parte (ou seja, realizaria apenas parcialmente a liberdade e a igualdade, a justiça e a democracia, etc). "A crítica imanente", de acordo com Cohen, "consiste em um projeto duplo: (1) tematizar e abrir à discussão aqueles princípios normativos inerentes às estruturas políticas modernas que deveriam informar a práxis social e política; e (2) demonstrar as constrições institucionais que impediam sua atualização na sociedade moderna (crítica da dominação e da estratificação)". ${ }^{29} \mathrm{E}$ fundamental no argumento de Cohen o fato de que pensar a "sociedade civil" não implicava vincular o "sistema das necessidades" com aquilo que constituirá sua anatomia nos textos posteriores, a saber, o trabalho e o modo de produção capitalista. Uma vez que Marx ainda não havia reduzido a sociedade civil e o Estado às determinações da economia, ele teve de fazer uma "crítica imanente" que simplesmente extraísse os princípios normativos das democracias modernas e contrastá-los com aquelas instituições que impediriam sistematicamente a realização desses mesmos princípios. "Democracia" significaria, de acordo com a explicação de Draper, "a união do Estado com o povo. Ela conota uma sociedade em que a separação entre o social e o político é transcendida, em que o universal e o particular não mais se opõem, em que o Estado não se encontra mais alienado da sociedade civil, e, por sua vez, esta sociedade civil não é mais meramente a esfera do interesse individual". ${ }^{30}$ Pela primeira vez, diz Marx, é possível com a democracia "a verdadeira unidade do universal e do particular". ${ }^{31}$

É ainda mais importante notar o fato de que a qualidade humana mais fundamental, ou seja, a práxis, seria localizada por Marx no interior da sociedade política. Marx entenderia tal práxis como uma capacidade de autodeterminação política por meio da

29. Idem, p. 29. Sobre a questão da "crítica imanente" em Marx, cf. ainda Wellmer, A. Kritische Gesellschaftstheorie und Positivismus. Frankfurt/M: Suhrkamp, 1969, p. 83-4.

30. Draper, H. Karl Marx's theory of revolution I: The state and bureaucracy, p. 86.

31. Marx, K. Kritik des Hegelschen Staatsrechts. In: Engels, F.; MarxEngels Werke. Band 1, p. 231. 
interação com os outros em razão dos interesses da comunidade. A participação dos indivíduos na vida política - e não o "trabalho", que será constitutivo a partir dos Manuscritos de 1844 - seria a verdadeira expressão de sua humanidade. Mas na medida em que o Estado moderno emerge com suas instituições políticas pretensamente universais (parlamento, burocracia, exército, polícia, tribunais, etc.), mantém-se uma estratificação social e, por conseguinte, uma esfera de indivíduos apoliticos, unidos apenas pelas necessidades e interesses privados e que dependem mutuamente da divisão do trabalho e do mercado. À sociedade civil delega-se não um espaço de autodeterminação, de atividade autônoma, mas de alienação politica própria de um individualismo irrestrito. Ora, não haveria nessa formulação do jovem Marx uma consideração meramente funcionalista dos princípios normativos da república democrática, tal como nos textos posteriores, pois a idéia de soberania popular, autonomia, igualdade, democracia, etc., possibilitariam a realização justamente dessa autodeterminação política - e que, na visão contemporânea de Cohen, seria fundamental ainda hoje para "instruir os movimentos sociais contra a exclusão e a igualdade política”. ${ }^{2}$

O que definiria, além disso, a inclusão da questão do "social" em seus primeiros escritos reside na constatação de Marx de que haveria na própria sociedade civil uma estratificação primária que adotava uma forma de dominação apolítica, ou seja, que não se mostrava na sua articulação meramente política (nos modos de representação no interior do Estado). A posse ou falta da propriedade e a liberdade ou a necessidade de exercer trabalho assalariado são os fatores determinantes de sua análise de classe no interior da sociedade civil. Marx identifica assim uma classe de trabalhadores assalariados que, apesar de seu papel central para a reprodução econômica da sociedade, seria excluída de todos os

32. Cohen, J. Class and civil society: The limits of marxian critical theory, p. 33. Essa também é a leitura encontrada em Behre, J. Volkssouveränität und Demokratie: Zur Kritik staatszentrierter Demokratievorstellungen. Hamburg: VSA, 2004. Embora o autor mantenha tal interpretação inclusive para as obras maduras de Marx. 
benefícios materiais alcançados e, não obstante, veria também seus direitos serem sistematicamente violados. É importante notar que a superação dessa estratificação social ocorreria, nesse momento, por meio de uma práxis de autodeterminação que incluísse as necessidades dessa classe na demanda política da sociedade. Por essa razão, insistindo na soberania popular, Marx defende a participação de todos, pois as questões do Estado, por natureza, concernem a todos: "A tendência da sociedade civil de transformar-se em sociedade política, ou de fazer da sociedade política a sociedade real, mostra-se como a tendência, a mais universal possível, à participação no poder legislativo". ${ }^{33}$

Ora, o que caracterizaria a ação autônoma para uma sociedade civil individualista seria o fato de ser motivada somente no interesse, o qual significaria a expressão da alienação a uma necessidade específica do capitalismo. Apenas uma transformação radical das necessidades, ou seja, somente a abolição da estrutura dos interesses, libertaria os indivíduos da alienação. A sociedade civil burguesa e o Estado não possibilitariam a plena realização das necessidades radicai ${ }^{34}$, a efetivação de valores que pudessem promover a abundância e o enriquecimento das capacidades individuais e coletivas. A crítica de Marx já se dirigia assim "à limitação do desenvolvimento de necessidades múltiplas a um estrato social particular", os "proprietários". 35

Contudo, abandonando a perspectiva da "crítica imanente" presente no livro de 1843, Marx buscará uma determinação positiva capaz de superar o sistema de interesses ao interpretar, com base no conceito de trabalho, o proletariado como a única classe capaz de desenvolver tais "necessidades radicais". Será, portanto, nos seus Manuscritos de 1844 que ele passa a integrar no conceito de trabalho aquilo que compreende como uma atividade especí-

33. Marx, K. Kritik des Hegelschen Staatsrechts, In: Engels, F.; MarxEngels Werke. Band 1, p. 133.

34. Cf. Heller, A. Theorie der Bedürfnisse bei Marx. Westberlin: Vsa, 1987, principalmente p. 85-107; e Fraser, I. Hegel, Marx, and the concept of need. Edinburgh: Edinburgh University Press, 1998, p. 28 e 33-6.

35. Cohen, J. Class and civil society: The limits of marxian critical theory, p. 68. 
fica da classe trabalhadora, a saber, o trabalho como alienação e simultaneamente como potencial emancipatório de realização futura das necessidades - identificando, posteriormente, a realização de um "sistema de necessidades radicais" à constituição de uma sociedade de "produtores associados". ${ }^{36}$

A partir de sua primeira crítica da economia política, Marx apresenta o conceito de trabalho segundo seu referencial econômico (em que a atividade produtiva está estreitamente atrelada à forma histórica específica do trabalho assalariado) ou de acordo com uma noção mais filosófica de objetivação (um processo por meio do qual os indivíduos criam materialmente e satisfazem suas diferentes e variadas necessidades). No primeiro caso, tratase da atividade heterônoma a que está submetido o proletariado: o trabalho transforma a atividade do indivíduo em um meio forçado de sobrevivência, o separa da coletividade, não permite que se reconheça no seu próprio produto e o sujeita à dominação de um sistema anônimo e independente de sua vontade. No segundo caso, a atividade autônoma, impossibilitada pelo capitalismo, consiste em entender o trabalho não apenas como expansão das capacidades e necessidades, mas também como condição de possibilidade da própria liberdade. E principalmente no contexto de seu "materialismo histórico" - em que se abandona uma imagem expressivista de trabalho por um conceito reduzido à noção economicista e unilateral de produção (ou seja, trabalho em geral) - a força motriz da história passa a residir no conflito entre forças produtivas e relações de produção, de sorte que a superação do capitalismo se funda na possibilidade de desenvolvimento e reapropriação coletiva das forças produtivas. Ao romper com os entraves à expansão das necessidades, da produção e das capacidades de autorealização, o capitalismo criaria as condições para a universalização das necessidades - embora sua plena realização se encontrasse bloqueada em condições de trabalho heterônomo, ou seja, sob o modo de produção capitalista. Apesar das diferenças que os conceitos de trabalho e de forças produtivas assumem nos textos de Marx, o importante consiste em frisar que "as lutas por

36. Cf. Lange, E. M. Das Prinzip Arbeit. Berlin: Ulstein, 1980, pp. 11 e ss. 
emancipação podem agora ser travadas em nome das legitimações internas do próprio capitalismo: universalidade, desenvolvimento e satisfação". ${ }^{37}$

Nessa nova chave conceitual, o conceito de práxis política teria de ser pensado a partir do desenvolvimento das forças produtivas de modo que tal desenvolvimento não se opusesse a uma teoria revolucionária da luta de classes. Seria necessário identificar a auto-atividade dos indivíduos e das classes com o próprio desenvolvimento das forças produtivas. $\mathrm{O}$ conceito do político, intimamente dependente da idéia de revolução, corresponderia somente à transformação do modo de produção que, por meio de uma revolução social, resultaria em um produto social coletivo. Contudo, haveria uma tendência em assimilar a lógica da revolução proletária ao modelo revolucionário levado a cabo pela burguesia, pois seu fim último residiria no desenvolvimento posterior das forças produtivas iniciado pela burguesia. Ao reduzir as relações sociais às relações econômicas, segundo Cohen, sua teoria das classes nunca pôde romper com o "espelho da produção" e, portanto, acabaria por limitar o potencial da ação humana exatamente como o fez a sociedade capitalista a que Marx se opôs:

É irônico que Marx atribua ao proletariado a essência idêntica à qual a sociedade burguesa tentou reduzi-lo - força de trabalho. Definida segundo a universalidade da força de trabalho e baseada na lógica racionalista típica da consciência 'burguesa', a classe dos proletários, para ser consistente, tem de assumir a tarefa iniciada pela burguesia - a finalidade da produção e sua racionalização. ${ }^{38}$

Nesse sentido, a atividade e a luta política dos trabalhadores permaneceriam atreladas ao modelo de classe burguês, repondo na práxis proletária aspectos da realidade que a burguesia havia antes criado para si mesma. Cohen insiste que as lutas proletárias teriam de ser entendidas antes como luta contra a racionalidade capitalista produtivista e seus imperativos, como criação de formas de organização e demandas que expressariam necessidades radicais por

37. Cohen, J. Class and civil society: The limits of marxian critical theory, p. 73.

38. Idem, p. 103. 
novas formas de vida e novos valores que pudessem se apresentar como uma alternativa à dominação presente.

Somente em seus textos histórico-políticos seria possível romper, de alguma forma, com o paradigma produtivista para a compreensão de seu conceito do político. Embora, ainda assim, os textos sejam perpassados por uma justaposição de dois modelos de atividade política e revolucionária: por um lado, uma análise que identifica um constante processo no qual a dinâmica política envolve uma complexa mistura de necessidades (não diretamente ligadas à objetivação), tradição e símbolos; e, por outro lado, o cálculo racional do interesse de classe que penetra a dinâmica complexa do jogo político. Desse modo, Marx confrontaria seu rico "processo de análise" dos acontecimentos políticos nesses textos com um "esquema interpretativo" que resultaria reducionista. Nos escritos histórico-políticos surgiria uma noção de luta política e de história bem diferente daquela do materialismo histórico:

A tradição, os mitos, uma compreensão não reducionista dos símbolos e da ideologia, da ação revolucionária e da política não determinada pelos interesses meramente econômicos, mas motivada por uma pluralidade de significados, necessidades e motivos que são reelaborados a partir do passado. ${ }^{39}$

Em vez de reconhecer os processos políticos e acontecimentos históricos como interesse de classe, as rupturas radicais são motivadas por um conjunto de necessidades, valores, tradições, aspirações utópicas, etc., que ressurgem de um passado sempre por se completar em novas combinações e novos significados, mantendo em aberto a determinação do sentido da emancipação. ${ }^{40}$

Cohen nota, porém, que "o que Marx oferece com uma mão, ele tira com a outra". A "brilhante" análise e descrição que remete à importância dos símbolos e tradições do passado, que se mesclavam com uma pluralidade de necessidades, interesses e idéias, e

39. Idem, p. 113.

40. Cf. Draper, H. Karl Marx's theory of revolution I: The state and bureaucracy, principalmente parte II. 
que compunham em conjunto a motivação da atividade histórica, é diluída pela avaliação de Marx de acordo com a qual tal processo não seria impulsionado senão por uma grande ilusão que obscureceria a consciência revolucionária. Ao interpretar tais acontecimentos, ele procuraria desmistificar as ilusões, mitos e tradições incessantes que ainda pesavam sobre a consciência dos atores e que ocultavam suas relações e interesses de classe. $\mathrm{Na}$ verdade, o ponto de referência consiste no ideal de uma revolução proletária verdadeiramente universal que se realizaria unicamente em nome de um interesse de classe, o qual pela primeira vez representaria o interesse de toda a sociedade e, portanto, não necessitaria escrever sua poesia a partir do passado.

Seria no Capital, na formulação madura de sua crítica da economia política, que Marx concluiria a substituição de uma crítica imanente da sociedade civil pelo conceito de "modo de produção". Segundo Cohen, a teoria da evolução histórica materialista dá lugar a uma análise das formações sociais que parte de uma distinção entre "lógica e gênese histórica". ${ }^{41}$ Com esta distinção, seria possível apresentar pela primeira vez a economia como uma totalidade sistêmica cuja lógica é fundamental para a reprodução das relações sociais. Por um lado, os imperativos do processo específico de autovalorização do capital criam uma subordinação total dos indivíduos à economia. Com isso, não apenas as raízes da alienação, mas também a própria constituição privilegiada da identidade de classe do proletariado residiria unicamente no modo de produção capitalista. ${ }^{42}$ Por outro lado, ao vincular estreitamente o conceito de classe ao modo de produção capitalista, a riqueza da crítica madura da economia política representaria um empobrecimento se comparada com a "crítica

41. Cohen, J. Class and civil society: The limits of marxian critical theory, p. 114. Ver também Giannotti, J. A. Origens da dialética do trabalho, p. 182-94; e Reichelt, H. Zur logischen Struktur des Kapitalbegriffs bei Karl Marx. Freiburg: ça ira, 2001, capítulo 3.

42. Cf. a explicação de Draper para o que este entende ser o que caracteriza o conceito de classe em Marx a partir de determinações específicas do modo de produção capitalista, em Draper, H. Karl Marx's theory of revolution I: The state and bureaucracy, p. 33-48. 
imanente" da sociedade civil no que diz respeito à concepção de práxis política em causa: no Capital, "a relação com a práxis é somente determinista e arbitrária”. ${ }^{43}$

Se as classes e as lutas entre as classes são constituídas pela lógica reprodutiva do capital, se o proletariado é fundido, homogeneizado e posto pelo próprio capital como um momento de seu próprio processo de valorização, se essa lógica - juntamente com o mercado - impõe uma estrutura de interesses sobre as necessidades individuais daqueles que participam como agentes da produção, "em que base se pode argumentar", pergunta Cohen, "que a auto-constituição desses agentes da produção em uma classe que se opõe ao capital pode ser algo a mais do que a afirmação subjetiva da lógica do próprio capital?”. ${ }^{44}$ As lutas de classes que possibilitam o desenvolvimento das forças produtivas parecem levar adiante a lógica presente na produção capitalista, e não constituir uma práxis autônoma que contesta tal lógica de maneira radical. Pois em muitas passagens "a barreira real à produção capitalista é o próprio capital’. A única possibilidade de ação revolucionária apresentada em $O$ Capital consistiria na unificação do proletariado na base da socialização e da homogeneização do trabalho, imanente ao processo de produção. Como representantes das forças produtivas socializadas, como personificação do trabalho social, o interesse "objetivo" do proletariado teria de consistir na abolição dos limites impostos pelo capital ao posterior desenvolvimento das forças produtivas e sua organização consciente de acordo com um plano centralizado. A interação política perderia sua dinâmica própria, pois haveria uma dedução de uma lógica da luta de classes a partir da lógica de reprodução capitalista e das suas contradições imanentes:

As últimas implicações da integração do conceito de classe social em uma dinâmica da produção, da transformação das classes em personificação das relações de produção, em suma, da lógica do capital como uma lógica de luta de classes, se torna evidente logo que essa lógica do desenvolvimento interno e das contradições

43. Cohen, J. Class and civil society: The limits of marxian critical theory, p. 50.

44. Idem, ibidem. 
passam a ditar a dinâmica da constituição da classe e da transformação histórica. ${ }^{45}$

Pois, como confirmaria o próprio Marx, "o desenvolvimento histórico das contradições de uma forma de produção existente é a única via histórica de sua dissolução e de uma nova configuração". ${ }^{46}$

\section{IV}

A interpretação paradigmática de Cohen permite avaliar que o limite do conceito do político de Marx como orientação emancipatória consiste, assim, na sua restrição para dar conta de uma ampliação de demandas, atores, e questões a serem incluídos nas preocupações de uma teoria crítica contemporânea, pois as lutas emancipatórias que já não seriam mais localizadas no âmbito da classe trabalhadora acabariam sendo negadas ou consideradas zonas de conflitos marginais. Contudo, as relações entre capital e trabalho deram lugar a uma outra tipologia dos conflitos, ou seja, às lutas em torno da integridade e autonomia de diferentes formas de vida, espaços de autorrealização, conquistas de direito e autodeterminação política. Dessa outra perspectiva, a teoria das classes "exclui perigosamente a possibilidade (...) de poder haver outros modos de dominação que não as relações de classe sócio-econômicas, outros princípios de estratificação além de classe (nacionalidade, raça, status, sexo, etc.), outros modos de criação histórica e de interação que não o trabalho e a práxis revolucionária, outras fontes de motivação para a orientação da ação social, outras formas de interação política (participação) que não relações hierárquicas de poder, e outras maneiras de contestar a sociedade capitalista que não as lutas de classe em torno de necessidades radicais que emergem na dialética do trabalho". ${ }^{47}$

45. Idem, p. 174.

46. Marx, K. Das Kapital. Erster Band. In: Engels, F.; Marx-Engels Werke. Band 23. Berlim: Dietz Verlag, 1998, p. 512.

47. Cohen, J. Class and civil society: The limits of marxian critical theory, $\mathrm{p}$. 193. 
O modelo crítico do jovem Marx da Critica da filosofia do direito de Hegel, que partia das análises da sociedade civil, parece mais rico e cheio de conseqüências em relação à sua história dos efeitos porque estava centrado na realização radical da soberania popular por meio de um modelo de autodeterminação e interação políticas não circunscrito às relações econômicas:

Sem dúvida Marx permaneceu comprometido com os valores da liberdade pública, democracia, autonomia e igualdade, mas apenas em seus textos mais iniciais ele vislumbrou uma forma de democracia direta baseada no desenvolvimento posterior da sociedade civil, e não na sua abolição - uma forma que protegeria o indivíduo e o integraria na sociedade e no Estado por meio de sua própria participação ativa. ${ }^{48}$

Nesse contexto de juventude, a realização das "necessidades radicais" da comunidade política não estava limitada aos interesses privilegiados de uma única classe, permitindo uma recepção mais rica ao olhar voltado para os desafios da política contemporânea, pois não podemos continuar pressupondo que os interesses de classe ainda representem legitimamente todas as necessidades que compõem a pluralidade e a complexidade da dinâmica dos conflitos políticos, os quais não são mais determinados pelas relações econômicas entre capital e trabalho. De outra forma, não é possível levar adiante uma ampliação do conceito do político. Mas a reconstrução dessa nova gramática da luta social nos remete a uma outra história. ${ }^{49}$

\section{Bibliografia}

ALTHUSSER, L. Pour Marx. Paris: Librairie François Maspero, 1966. ANDERSON, P. Consideraçôes sobre o marxismo ocidental. São Paulo: Boitempo, 2004.

48. Idem, p. 35.

49. Cf. Melo, R. S. Sentidos da emancipação: Para além da antinomia revolução versus reforma, capítulo 3; e Nobre, M. "Teoria crítica hoje". In: Keinert, M. et. alt. (org.) Tensões e passagens: Filosofia crítica e modernidade. São Paulo: Singular/Esfera Pública, 2008. 
ARANTES, P. Um departamento francês de ultramar. São Paulo: Paz e Terra, 1994.

BAUDRILLARD, J. Le miroir de la production. Ou, l'illusion critique du matérialisme historique. Paris, 1985.

BEHRE, J. Volkssouveränität und Demokratie: Zur Kritik staatszentrierter Demokratievorstellungen. Hamburg: VSA, 2004.

BENHABIB, S. Critique, norm and utopia. New York: Columbia University Press, 1986.

CASTORIADIS, C. L'Institution imaginaire de la Societé. Paris: Éditions du Seuil, 1975.

COHEN, J. Class and civil society: The limits of marxian critical theory. Amherst: University of Massachussets Press, 1982.

DRAPER, H.“New social-democrat reformism”. In In: New Politics, v2, n. 2.New York: Monthly Review Press , 1963.

. Karl Marx's theory of revolution: The state and bureaucracy. New York: Monthly Review Press, 1977.

. Karl Marx's theory of revolution: The politics of social classes. New York: Monthly Review Press, 1978.

DUBIEL, H. Ungewißheit und Politik. Frankfurt/M: Suhrkamp, 1994.

FAUSTO, R. Marx - Lógica e política. Tomo I. São Paulo: Brasiliense, 1987.

FRASER, I. Hegel, Marx, and the concept of need. Edinburgh: Edinburgh University Press, 1998.

GIANNOTTI, A. Origens da dialética do trabalho. São Paulo: Difusão Européia do Livro, 1966.

. "Contra Althusser". In:

São Paulo: Vozes/CEBRAP, 1975.

Trabalho e reflexão. São Paulo: Brasiliense, 1984.

HABERMAS, J. Erkenntnis und Interesse. Frankfurt/M, Suhrkamp, 1968.

HEGEL, G. W. F. Grundlinien der Philosophie des Rechts. Frankfurt/M: Suhrkamp, 1986.

HELLER, A. Theorie der Bedürfnisse bei Marx. Westberlin: Vsa, 1987.

HONNETH, A.; JAEGGI, U. (org.). Theorien des Historischen Materialismus. Frankfurt/M: Suhrkamp, 1977.

Sofrimento de indeterminação: Uma reatualização da filosofia do direito de Hegel. Trad. de Rúrion Soares Melo. São Paulo: Esfera Pública, 2007. 
KEINERT, M.; et. alt. (org.) Tensões e passagens: Filosofia crítica e modernidade. São Paulo: Singular/Esfera Pública, 2008.

LANGE, E. M. Das Prinzip Arbeit. Berlin: Ulstein, 1980.

LOHMANN, G. Indiferenz und Gesellschaft. Frankfurt/M: Suhrkamp, 1991.

LÖWY, M. A teoria da revolução no jovem Marx. Trad. de Anderson Gonçalves. Petrópolis: Vozes, 2002.

LUKÁCS, G. História e consciência de classe. Trad. de Rodnei Nascimento. São Paulo: Martins Fontes, 2003.

MARX, K. Das Kapital. Erster Band. In: Engels, F.; .Marx-Engels Werke. Band 23. Berlim: Dietz Verlag, 1998. . Die Judenfrage. In: Engels, F.; Marx-Engels Werke. Band 1. Berlin: Dietz Verlag, 1961. Kritik des Hegelschen Staatsrechts. In: Engels, F.; MarxEngels Werke. Band 1. Berlin: Dietz Verlag, 1961.

MELO, R. S. Sentidos da emancipação: Para além da antinomia revolução versus reforma. São Paulo. Tese (doutorado). FFLCH-USP, 2009.

MEYER, T. Der Zwiespalt in der Marx'schen Emanzipationstheorie: Studie zur Rolle des proletarischen Subjekts. Kronberg, 1973.

NOBRE, M. Lukács e os limites da reificação. São Paulo: Ed. 34, 2001. A teoria crítica. Rio de Janeiro: Jorge Zahar, 2004. . (org.) Curso livre de teoria crítica. Campinas: Papirus, 2008. . "Teoria crítica hoje". In: KEINERT, M. et. alt. (org.) Tensões e passagens: Filosofia crítica e modernidade. São Paulo: Singular/Esfera Pública, 2008.

REICHELT, H. Zur logischen Struktur des Kapitalbegriffs bei Karl Marx. Freiburg: ça ira, 2001.

REISBERG, A. Von der I. zur II. Internationale. Die Durchsetzung des Marxismus um die Wiederherstelung der Arbeiterinternationale. Dietz, 1980.

RUNDELL, J. Origins of modernity: The origins of modern social theory from Kant to Hegel to Marx. Cambridge, 1987.

VRANICKI, P. Geschichte des Marxismus. 2 Bände. Frankfurt/M: Suhrkamp, 1997.

WELLMER, A. Kritische Gesellschaftstheorie und Positivismus. Frankfurt/ M: Suhrkamp, 1969. 